\title{
Chlorophyll $a+b$ content in leaves of spring wheat (Triticum aestivum L.) after application of MCPA and selected HILs
}

\author{
Zawartość chlorofilu a + b w liściach pszenicy jarej (Triticum aestivum L.) \\ po zastosowaniu MCPA oraz wybranych HILs
}

\author{
Marcin Grobela*
}

\section{Summary}

The aim of the study was to examine the effect of foliar application of three herbicidal ionic liquid forms of MCPA ([Arq 2HT][MCPA], [cocoBET][MCPA], [p-DADMA][MCPA]) on chlorophyll $a+b$ content in leaves of spring wheat. Spectrophotometric method was used to measure chlorophyll $\mathrm{a}+\mathrm{b}$ content 24,72 and $168 \mathrm{~h}$ after fields were treated with Chwastox Extra $300 \mathrm{SL}$ (a.s. MCPA). The data was compared to the control that consisted of a commercial formulation of MCPA as a salt. The field study revealed that a chlorophyll $\mathrm{a}+\mathrm{b}$ content measured $24 \mathrm{~h}$ after spraying with MCPA as a salt was higher by $17 \%, 72 \mathrm{~h}$ by $14 \%$ but $168 \mathrm{~h}$ it was lower by $16 \%$. The highest decreases in chlorophyll $\mathrm{a}+\mathrm{b}$ content were observed $168 \mathrm{~h}$ after application of Chwastox Extra $300 \mathrm{SL}$ compared to the control and [p-DADMA] [MCPA] and they were $16.2 \%$ and $17 \%$. However, in comparison with [Arq $2 \mathrm{HT}][\mathrm{MCPA}$ ] and [coco BET][MCPA] the results were similar and amounted to about $2.5 \%$. The results do not confirm a significant impact on the content of photosynthetic pigments in spring wheat. The application of HILs as an alternative herbicide also did not result in adverse chlorophyll $a+b$ decrease.

Key words: chlorophyll; herbicidal ionic liquids; MCPA; spring wheat

\section{Streszczenie}

Celem przeprowadzonych badań była spektrofotometryczna ocena zmian zawartości chlorofilu w liściach pszenicy jarej po 24, 72 i 168 h od momentu zastosowania opryskiwania środkiem Chwastox Extra 300 SL (s.cz. MCPA) oraz wybranymi herbicydowymi cieczami jonowymi HILs ([Arq 2HT][MCPA], [cocoBET][MCPA], [p-DADMA][MCPA]). Poziom chlorofilu a + b w pszenicy jarej po $24 \mathrm{~h}$, na którą zaaplikowano MCPA w postaci soli był wyższy o 17\%, a po $72 \mathrm{~h}$ o 14\%, natomiast po $168 \mathrm{~h}$ niższy o $16 \%$ w porównaniu do stężenia barwników roślin z obiektów kontrolnych. Największe spadki zawartości chlorofilu a + b zaobserwowano po $168 \mathrm{~h}$ dla herbicydu Chwastox Extra 300 SL w porównaniu do kontroli oraz [p-DADMA][MCPA] i wynosiły one 16,2\% oraz 17\%. Natomiast w porównaniu z [Arq $2 \mathrm{HT}$ ] [MCPA] i [coco BET][MCPA] uzyskane wyniki były podobne i wynosiły około 2,5\%. Dane jakie uzyskano nie potwierdzają istotnego wpływu stosowania MCPA na zawartość pigmentów fotosyntetycznych w pszenicy jarej. Aplikacja HILs jako herbicydu alternatywnego również nie wywołała niepożądanych efektów działania w postaci obniżenia zawartości chlorofilu a + b.

Słowa kluczowe: chlorofil; herbicydowe ciecze jonowe; MCPA; pszenica jara

Instytut Ochrony Roślin - Państwowy Instytut Badawczy

Władysława Węgorka 20, 60-318 Poznań

*corresponding author: grobela@iorpib.poznan.pl 


\section{Wstęp / Introduction}

Chlorofile są szeroko rozpowszechnioną grupą barwników fotosyntetycznych występujących w roślinach wyższych, glonach oraz cyjanobakteriach. Chlorofil jest niezbędnym pigmentem pełniącym kluczową rolę $\mathrm{w}$ prawidłowym przebiegu fotosyntezy, w której zamiana energii światła na energię wiązań chemicznych jest możliwa dzięki absorpcji kwantów światła w reakcjach redoks (Mackinney 1941; Baker 2008). Dlatego też, stężenie chlorofilu w liściach może bezpośrednio wpływać na przebieg fotosyntezy w roślinie (Croft i wsp. 2017). Przebieg i wydajność procesu fotosyntezy związana jest również z zapotrzebowaniem roślin na makro- i mikroelementy, przede wszystkim azot i potas (Bojović i Stojanović 2005), ale również magnez (Ceylan i wsp. 2016; Tatagiba i wsp. 2016; Tränkner i wsp. 2016) i żelazo, które jest aktywatorem syntezy chlorofilu (Politycka 2007).

Nowoczesne rolnictwo, poprzez stosowanie środków ochrony roślin, może przyczyniać się do wystąpienia w roślinie stresu abiotycznego (Devine i Shukla 2000). Konsekwencją wystąpienia takiego stresu może być ograniczona produkcja fotosyntetyczna, degradacja chlorofili, a także konieczność uruchomienia przez rośliny procesów związanych z adaptacją do niekorzystnych warunków środowiskowych (Starck 2008). W zależności od budowy substancji czynnych i ich właściwości mogą one prowadzić do zmian strukturalnych białek, lipidów, kwasów nukleinowych oraz chlorofilu, zaburzając prawidłowy przebieg niektórych szlaków metabolicznych (Ekmekci i Terzioglu 2005). W badaniach własnych Wang i Zhou (2006) oraz Žaltauskaitè i Brazaitytè (2013) stwierdzili zmniejszoną zawartość chlorofilu w roślinach po zastosowaniu chlorimurynu etylu oraz amidosulfuronu. Kobyłecka i Skiba (2008) oraz Grobela (2016) sugerują, że MCPA posiada większą tendencję do wiązania kationów metali dwuwartościowych, a tym samym blokowania ich dostępności dla roślin. Analizy prowadzone przez Łozowicką i wsp. (2016) pokazują, że stosowanie herbicydów zawierających w swoim składzie MCPA i dikambę spowodowało spadek zawartości chlorofilu w roślinach, jednakże łączne stosowanie tych substancji czynnych z tiofanatem metylu i azoksystrobina przyczyniało się do wzrostu jego stężenia w liściach trzech odmian pszenicy jarej. Gao i wsp. (2012) dowodzą natomiast, że wraz ze wzrostem stężenia MCPA następuje spadek zawartości chlorofilu, w tym samym okresie wzrostu, dla Agrostis stolonifera L. Natomiast Tatarková i wsp. (2013) wykazują, że obecność MCPA w glebie nie ma znaczącego wpływu na zawartość chlorofilu w liściach Helianthus annuus L. Podobne wnioski płyną z badań Žaltauskaite i Kišonaitė (2014), gdzie stosowanie MCPA przyczyniło się do zmniejszenia suchej masy łodyg i korzeni Triticum aestivum L., bez wywołania znaczącego wpływu na zawartość chlorofili w tkankach roślinnych.
W ostatnim czasie pojawia się dużo prac związanych z możliwością zastosowania cieczy jonowych z wprowadzonym w ich strukturę anionem o działaniu chwastobójczym, dzięki czemu można uzyskać nową generację herbicydów, tzw. herbicydowe ciecze jonowe (HILs) (Pernak i wsp. 2011, 2013). Stosowanie ich mogłoby zmniejszyć negatywne skutki środowiskowe związane z używaniem tradycyjnych herbicydów (Hough i wsp. 2007; Pernak i wsp. 2011; Shamshina i wsp. 2015), ponieważ wykazują się one mniejszą mobilnością w glebie oraz wodach gruntowych. Ponadto HILs posiadają wysoką aktywność powierzchniową, co niweluje potrzebę stosowania adiuwantów. Dzięki tym właściwościom dawka substancji czynnej w herbicydowych cieczach jonowych może być znacznie obniżona w stosunku do tradycyjnych formulacji z jednoczesnym zachowaniem ukierunkowanych właściwości biologicznych i wybranych właściwości fizykochemicznych (Praczyk i wsp. 2012; Pernak i wsp. 2013; Grobela 2016).

Celem badań była ocena łącznej zawartości chlorofilu a i b w liściach pszenicy jarej po zastosowaniu MCPA oraz wybranych herbicydowych cieczy jonowych. Badania zostały przeprowadzone w warunkach polowych.

\section{Materiały i metody / Materials and methods}

W badaniach zastosowano dostępną w handlu formulację MCPA w postaci soli sodowo-potasowej [Chwastox Extra 300 SL (Ch300), producent Zakłady Chemiczne Organika-Sarzyna S.A. Nowa Sarzyna, Polska], a także będące $\mathrm{w}$ fazie badań herbicydowe ciecze jonowe: [Arq 2HT] [MCPA] (Arq 2HT) (4-chloro-2-metylofenoksy)octan ditallowdimetyloamoniowy, [coco BET][MCPA] (coco BET) (4-chloro-2-metylofenoksy)octan cocoamidopropylobetainy oraz [p-DADMA][MCPA] (p-DADMA) (4-chloro2-metylofenoksy)octan poli(diallilodimetyloamoniowy) (rys. 1). Herbicydowe ciecze jonowe zostały zsyntetyzowane w Zakładzie Technologii Chemicznej Politechniki Poznańskiej oraz opisane przez Pernaka i wsp. (2011, 2016), Giszter i wsp. (2013) oraz Kordala-Markiewicz i wsp. (2014).

Badania mikropoletkowe prowadzone były w 2016 roku w Terenowej Stacji Doświadczalnej w Winnej Górze

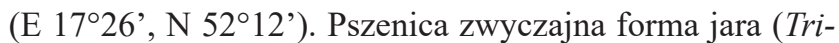
ticum aestivum L.) odmiany Bombona uprawiana była na poletkach doświadczalnych o powierzchni $16,5 \mathrm{~m}^{2}$. Doświadczenie założono w układzie losowanych bloków, w 4 powtórzeniach z uwzględnieniem poletek kontrolnych. Jako substancję odniesienia użyto handlowo dostępny herbicyd Ch300. Ch300 (roztwór wodny) oraz HILs [roztwór woda/etanol $(1: 1 \mathrm{v} / \mathrm{v})]$ aplikowano w takiej dawce, aby stężenie substancji czynnej było takie samo i wynosiło $900 \mathrm{~g} / \mathrm{ha}$. Roztwory stosowano w fazie rozwojowej 4 liści 
a)<smiles>Cc1cc(Cl)ccc1OCC(=O)[O-]</smiles>

b)<smiles>Cc1cc(Cl)ccc1OCC(=O)[O-]</smiles><smiles>[R][N+]([R])(C)C</smiles>

c)<smiles>Cc1cc(Cl)ccc1OCC(=O)[O-]</smiles><smiles>C[N+](C)(CCCNC(=O)O)CC(=O)O</smiles>

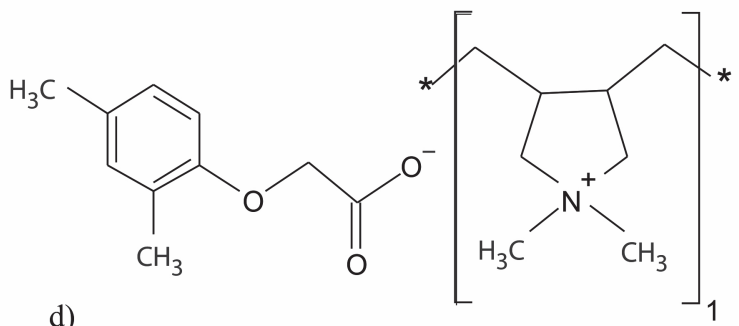

Rys. 1. Wzory strukturalne użytych herbicydów oraz HILs: a) sól MCPA, b) [Arq 2HT][MCPA], c) [coco BET][MCPA], d [p-DADMA] [MCPA]

Fig. 1. Structural formulas of applied herbicides and HILs: a) salt MCPA, b) [Arq 2HT][MCPA], c) [coco BET][MCPA], d [p-DADMA] [MCPA]

(BBCH 14), a aplikacji dokonano opryskiwaczem plecakowym Aporo (Poznań, Polska) wyposażonym w dysze płaskostrumieniowe TeeJet ${ }^{\circledR}$ DG110/02 (TeeJet Technologies, Wheaton, IL, USA) o wydajności 200 1/ha przy ciśnieniu roboczym 0,3 $\mathrm{MPa}$.

Rośliny do oznaczeń chlorofilu pobrano losowo z każdego poletka doświadczalnego. Analizie zostały poddane najmłodsze, w pełni rozwinięte liście. Zawartość chlorofilu oznaczona została zgodnie z metodą Arnona i wsp. (1956), z modyfikacją Lichtenthalera i Wellburna (1983). Do około 0,5 g schłodzonych liści dodano 5-10 $\mathrm{ml} \mathrm{80 \%} \mathrm{acetonu,} \mathrm{oko-}$ ło $0,1 \mathrm{~g} \mathrm{CaCO}_{3}$ i piasku kwarcowego, wszystko dokładnie roztarto w moździerzu, przeniesiono ilościowo i przesączono do kolby miarowej. Moździerz dokładnie przemyto małymi porcjami $80 \%$ acetonu. Końcową objętość przesączu ustalono na $50 \mathrm{ml}$. Oznaczenia zawartości chlorofilu dokonano przy pomocy spektrofotometru HACH Lange DR 5000 przy długościach fal: 645 oraz $663 \mathrm{~nm}$.

Wyniki zawartości chlorofilu a $+\mathrm{b}$ [mg/g ś.m.] obliczono według wzoru:

$\left.\mathrm{C}_{\mathrm{chl}(\mathrm{a}+\mathrm{b})}=\left(8,02 \times \mathrm{A}_{(663)}+20,2 \times \mathrm{A}_{(645)}\right) \times((\mathrm{V} / 1000) \times \mathrm{w})\right)$

A 645-663 - wartość absorbancji mierzonej przy długości fali 645-663 nm,

$\mathrm{V}$ - całkowita objętość ekstraktu [ml],

$\mathrm{w}$ - masa próbki [g],

8,02 i 20,2 - współczynnik przeliczeniowy.

Do wyznaczenia relacji między zawartością chlorofilu w liściach pszenicy jarej, zastosowanego preparatu oraz terminu poboru próbek w korelacji z próbą kontrolną (woda lub woda/etanol) stworzono model liniowy, którego założenia były weryfikowane na podstawie wykresów diagno- stycznych (Bates i wsp. 2015; Lenth 2016; R Core Team 2016).

\section{Wyniki i dyskusja / Results and discussion}

Współczesne rolnictwo wymaga nieustannego rozwoju innowacyjnych praktyk rolniczych, których zastosowanie pozwoli na optymalizację zysków i minimalizację szkód środowiskowych wywołanych stosowaniem pestycydów. W tej sytuacji poszukuje się alternatywnych metod ochrony roślin wykazujących wysoką skuteczność w niskich dawkach, co mogą gwarantować herbicydowe ciecze jonowe (Praczyk i wsp. 2012).

Z przeprowadzonego doświadczenia wynika, że stosowanie powszechnie dostępnego herbicydu Chwastox Extra $300 \mathrm{SL}$ (s.cz. MCPA) po $24 \mathrm{i} 72 \mathrm{~h}$ od momentu aplikacji nie spowodowało znaczących zmian w zawartości chlorofilu a + b w liściach pszenicy jarej, chociaż jego zawartość była wyższa w porównaniu z próbą kontrolną o około $15 \%$. Analizy przeprowadzone po $24 \mathrm{~h}$ od aplikacji cieczy roboczych wykazały największą zawartość chlorofilu w obiekcie Ch300 i była ona większa odpowiednio o 12,3\% oraz 10,9\% w porównaniu z Arq $2 \mathrm{HT}$ i coco BET, natomiast dla p-DADMA różnica ta wyniosła 3,82\%. Podobne tendencje odnotowano po $72 \mathrm{~h}$ trwania eksperymentu. Najwyższą zawartość chlorofilu oznaczono w obiekcie Ch300 i była ona większa o $35,9 \%, 24,8 \%$ i 14,0\% niż w obiektach coco BET, p-DADMA i Arq 2HT. Natomiast po 168 h zauważono, że zawartość chlorofilu a + b w liściach pszenicy jarej dla Ch300 była niższa w porównaniu z próbą kontrolną o około 16,3\%. W zestawieniu Ch300 z HILs różnica ta wy- 


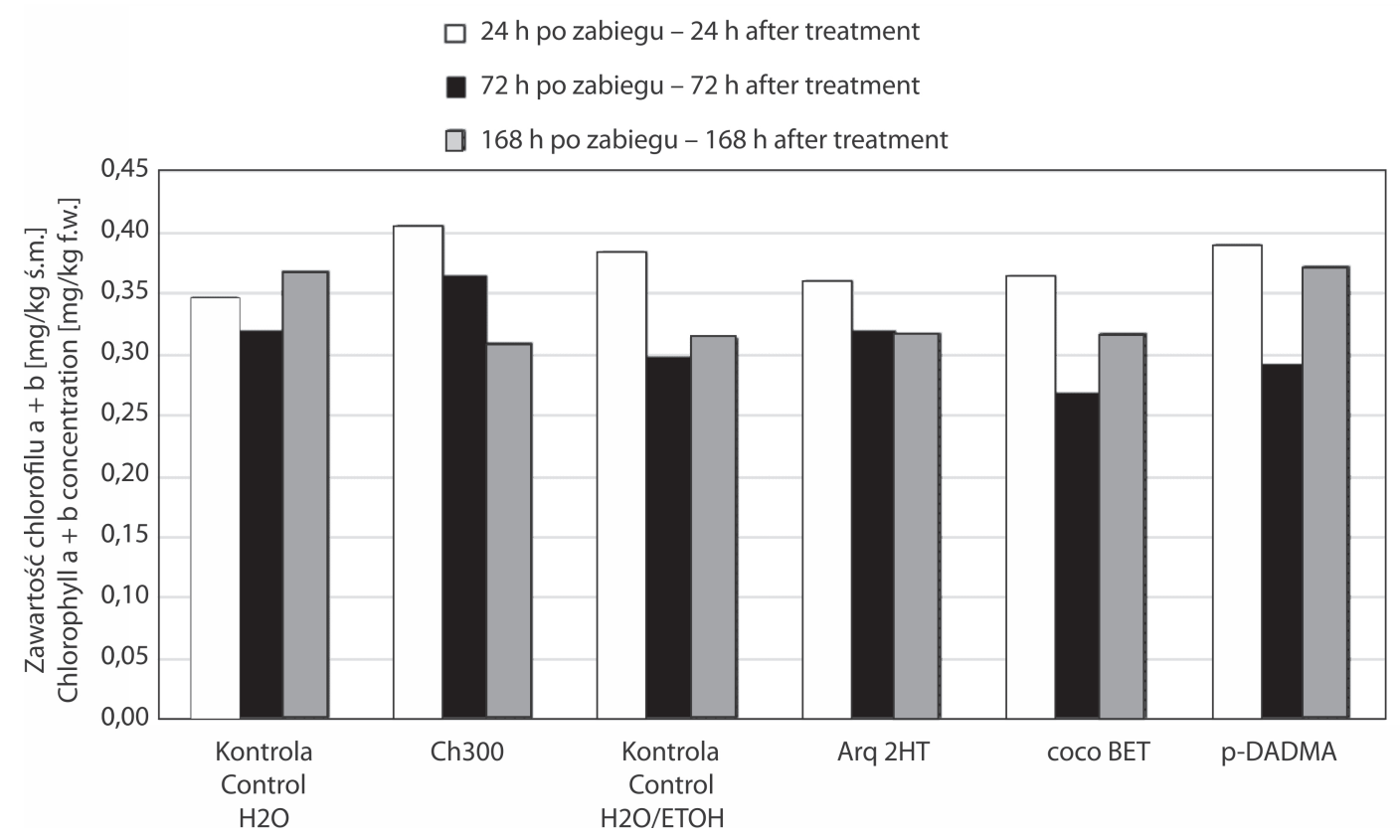

Rys. 2. Zawartość chlorofilu a $+\mathrm{b}$ w liściach pszenicy jarej po 24, 72 i 168 h od zastosowanego zabiegu Ch300 oraz HILs

Fig. 2. Chlorophyll $\mathrm{a}+\mathrm{b}$ content after treatment of Ch300 and HILs after 24, 72 and $168 \mathrm{~h}$ in leaves of spring wheat

nosiła dla Arq 2HT jedynie 2,5\%, dla coco BET 2,6\%, a dla p-DADMA już około $17 \%$ (rys. 2).

Wyniki regresji liniowej nie pozwalają na odrzucenie hipotezy zerowej o braku różnic we wszystkich trzech badanych terminach ( 24 h, 72 h, 168 h), zarówno między próbami kontrolnymi (różnica pomiędzy średnimi: 0,0545, $\mathrm{p}=0,0665)$, tj. wodą oraz woda/etanol, jak i różnicy pomiędzy poszczególnymi środkami a próbą kontrolną - woda/ etanol. W terminie trzecim najmniejszą różnicę pomiędzy średnimi zanotowano dla Arq 2HT i kontroli woda/etanol: $0,00275, p=0,9226$, a największą dla p-DADMA i kontroli woda/etanol: $0,058, \mathrm{p}=0,0522$, jednak w tym przypadku należy zauważyć, że kontrola $\mathrm{z}$ wodą również różniła się w podobnym stopniu od kontroli woda/etanol, tj: 0,0545, $\mathrm{p}=0,0665$. Inspekcja wykresów diagnostycznych nie pozwoliła na stwierdzenie znaczących odstępstw od założeń regresji liniowej (tj. normalności rozkładu błędu oraz homoskedastyczności) (tab. 1).

Wyniki przeprowadzonych badań wskazują, że stosowanie Ch300 oraz nowych HILs nie wywarło znaczącego wpływu na zawartość chlorofilu a + b w liściach pszenicy jarej po 24, 72 i 168 h od momentu zastosowania opryski-

Tabela 1. Oszacowanie podstawowych kontrastów z uwzględnieniem statystycznie istotnych różnic $(\mathrm{p}<0,05)$ dla przeprowadzonych zabiegów

Table 1. Estimate of basic contrasts with significant differences $(\mathrm{p}<0.05)$ conducted for treatments

\begin{tabular}{|c|c|c|c|c|c|c|c|c|c|}
\hline \multirow{2}{*}{$\begin{array}{c}\text { Obiekt } \\
\text { Treatment }\end{array}$} & \multicolumn{3}{|c|}{ Termin $1(24 \mathrm{~h})$ - Time $1(24 \mathrm{~h})$} & \multicolumn{3}{|c|}{ Termin $2(72 \mathrm{~h})-$ Time $2(72 \mathrm{~h})$} & \multicolumn{3}{|c|}{ Termin $3(168$ h) - Time 3 (168 h) } \\
\hline & estimate & $t$ ratio & $p$ value & estimate & $t$ ratio & $p$ value & estimate & $t$ ratio & $p$ value \\
\hline $\begin{array}{l}\text { Kontrola }^{\mathrm{a}} \\
\text { Control }^{\mathrm{a}}\end{array}$ & $-0,03875$ & $-1,104$ & 0,284 & 0,2150 & 0,641 & 0,5299 & 0,05450 & 1,953 & 0,0665 \\
\hline $\mathrm{Ch} 300^{\mathrm{b}}$ & 0,02025 & 0,577 & 0,571 & 0,06675 & 1,989 & 0,0622 & $-0,00525$ & $-0,188$ & 0,8529 \\
\hline $\begin{array}{l}\text { Kontrola } \\
\text { Control }^{c}\end{array}$ & 0,38478 & 15,496 & $<0,0001$ & 0,29900 & 12,598 & $<0,0001$ & 0,31375 & 15,901 & $<0,0001$ \\
\hline Arq $2 \mathrm{HT}$ & $-0,02425$ & $-0,691$ & 0,499 & 0,02200 & 0,655 & 0,5205 & 0,00275 & 0,099 & 0,9226 \\
\hline coco BET & $-0,01950$ & $-0,555$ & 0,585 & $-0,02975$ & $-0,886$ & 0,3871 & 0,00325 & 0,116 & 0,9086 \\
\hline p-DADMA & 0,00500 & 0,142 & 0,888 & $-0,00600$ & $-0,179$ & 0,8601 & 0,05800 & 2,079 & 0,0522 \\
\hline
\end{tabular}

${ }^{\mathrm{a}}$ zabieg wodny - water treatment

bherbicyd komercyjny - commercial herbicyde

${ }^{c}$ zabieg woda/etanol - water/ethanol treatment

estimate - oszacowanie średniej, $t$ ratio - stosunek średniej do błędu standardowego, $p$ value - prawdopodobieństwo popełnienia błędu I rodzaju 
wania. Zbliżone wyniki badań uzyskał Grobela (2017), który porównywał HILs ([Etq O-12][MCPA], [DDA][MCPA]) i Ch300 w odniesieniu do jęczmienia jarego. W przeprowadzonych badaniach stwierdzono, że zastosowanie komercyjnych środków ochrony roślin na bazie MCPA oraz badanych preparatów typu HILs nie powodowało statystycznie istotnych zmian w zawartości chlorofilu $\mathrm{a}+\mathrm{b}$ w liściach badanej rośliny. Uzyskane wyniki są zbliżone z badaniami Tatarkovej i wsp. (2013), Žaltauskaite i Kišonaite (2014) oraz Łozowickiej i wsp. (2016), gdzie aplikacja MCPA nie powoduje znaczącego obniżenia zawartości chlorofilu w liściach słonecznika, pszenicy i jęczmienia jarego.

\section{Wnioski / Conclusions}

1. Aplikacja herbicydu i cieczy jonowych zawierających MCPA wpłynęła na zróżnicowanie zawartości chlorofilu a + b w liściach pszenicy jarej.

2. Różnice w stosunku do obiektu kontrolnego były widoczne po 24 i 168 godzinach od aplikacji preparatów.

3. W przeprowadzonych badaniach zastosowanie komercyjnego herbicydu na bazie MCPA oraz preparatów typu HILs nie powodowało statystycznie istotnych różnic $\mathrm{w}$ zawartości chlorofilu $\mathrm{a}+\mathrm{b}$ w liściach pszenicy jarej.

\section{Literatura / References}

Arnon D.I., Allen M.B., Whatley F.R. 1956. Photosynthesis by isolated chloroplasts IV. General concept and comparison of three photochemical reactions. Biochimica et Biophysica Acta 20 (3): 449-461.

Baker N.R. 2008. Chlorophyll fluorescence: a probe of photosynthesis in vivo. Annual Review of Plant Biology 59 (1): 89-113. DOI: 10.1146/annurev.arplant.59.032607.092759.

Bates D., Maechler M., Bolker B., Walker S. 2015. Fitting linear mixed-effects models using lme4. Journal of Statistical Software 67 (1): 1-48. DOI: 10.18637/jss.v067.i01.

Bojović B., Stojanović J. 2005. Chlorophyll and carotenoid content in wheat cultivars as a function of mineral nutrition. Archives of Biological Sciences 57 (4): 283-290.

Ceylan Y., Kutman U.B., Mengutay M., Cakmak I. 2016. Magnesium applications to growth medium and foliage affect the starch distribution, increase the grain size and improve the seed germination in wheat. Plant Soil 406 (1-2): 145-156. DOI: 10.1007/s11104-0162871-8.

Croft H., Chen J.M., Luo X., Bartlett P., Chen B., Staebler R.M. 2017. Leaf chlorophyll content as a proxy for leaf photosynthetic capacity. Global Change Biology 23 (9): 3513-3524. DOI: 10.1111/gcb.13599.

Devine M.D., Shukla A. 2000. Altered target sites as a mechanism of herbicide resistance. Crop Protection 19 (8-10): 881-889. DOI: 10.1016/S0261-2194(00)00123-X.

Ekmekci Y., Terzioglu S. 2005. Effects of oxidative stress induced by paraquat on wild and cultivated wheats. Pesticide Biochemistry and Physiology 83 (2-3): 69-81. DOI: 10.1016/j.pestbp.2005.03.012.

Gao Y.F., Shi M.W., Wang J.H. 2012. The influence of chlorophenoxy herbicides MCPA on creeping bentgrass physiological index. Advanced Materials Research 356-360: 2763-2766. DOI: 10.4028/www.scientific.net/AMR.356-360.2763.

Giszter R., Niemczak M., Marcinkowska K., Walkiewicz F., Praczyk T., Pernak J. 2013. Nowe herbicydy poli(diallilodimetyloamoniowe). Synteza i aktywność biologiczna. [New polydiallyldimethylammonium herbicides. Synthesis and biological activity]. Przemysł Chemiczny 92 (9): 1602-1605.

Grobela M. 2016. Differences in the uptake of Mn, Zn, and Cu by Hordeum vulgare L. following applications of MCPA-based herbicides and their ionic liquid forms. Polish Journal of Environmental Studies 25 (5): 1931-1936. DOI: 10.15244/pjoes/62761.

Grobela M. 2017. Zawartość chlorofilu a + b w liściach jęczmienia jarego po zastosowaniu MCPA oraz wybranych HILs. [Chlorophyll $\mathrm{a}+\mathrm{b}$ content in leaves of spring barley after MCPA and selected HILs application]. Progress in Plant Protection 57 (1): 70-74. DOI: 10.14199/ppp-2017-012.

Hough W.L., Smiglak M., Rodríguez H., Swatloski R.P., Spear S.K., Daly D.T., Pernak J., Grisel J.E., Carliss R.D., Soutullo M.D., Davis J.H. Jr., Rogers R.D. 2007. The third evolution of ionic liquids: active pharmaceutical ingredients. New Journal of Chemistry 31 (8): 1429-1436. DOI: 10.1039/B706677P.

Kobyłecka J., Skiba E. 2008. The effect of phenoxyacetic herbicides on the uptake of copper, zinc and manganese by Triticum aestivum L. Polish Journal of Environmental Studies 17 (6): 895-901.

Kordala-Markiewicz R., Rodak H., Markiewicz M., Walkiewicz F., Sznajdrowska A., Materna K., Marcinkowska K., Praczyk T., Pernak J. 2014. Phenoxy herbicidal ammonium ionic liquids. Tetrahedron 70 (32): 4784-4789.

Lenth R.V. 2016. Least-squares means: The R package lsmeans. Journal of Statistical Software 69 (1): 1-33. DOI: $10.18637 /$ jss.v069. i01.

Lichtenthaler H.K., Wellburn A.R. 1983. Determinations of total carotenoids and chlorophylls a and b of leaf extracts in different solvents. Biochemical Society Transactions 11 (5): 591-592. DOI: 10.1042/bst0110591.

Łozowicka B., Wołejko E., Konecki R. 2016. Wpływ wybranych substancji czynnych fungicydów, herbicydów i ich terminów aplikacji na poziom barwników asymilacyjnych w Triticum aestivum L. [Influence of selected active substances of fungicides and herbicides and time of their application on chlorophyll content in Triticum aestivum L.]. Progress in Plant Protection 56 (2): 186-190. DOI: 10.14199/ ppp-2016-031.

Mackinney G. 1941. Absorption of light by chlorophyll solutions. Journal of Biological Chemistry 140: 315-322.

Pernak J., Niemczak M., Chrzanowski Ł., Ławniczak Ł., Fochtman P., Marcinkowska K., Praczyk T. 2016. Betaine and carnitine derivatives as herbicidal ionic liquids. Chemistry - A European Journal 22 (34): 12012-12021. DOI: 10.1002/chem.201601952. 
Pernak J., Niemczak M., Zakrocka K., Praczyk T. 2013. Herbicidal ionic liquid with dual-function. Tetrahedron 69 (38): 8132-8136. DOI: 10.1016/j.tet.2013.07.053.

Pernak J., Syguda A., Janiszewska D., Materna K., Praczyk T. 2011. Ionic liquids with herbicidal anions. Tetrahedron 67 (26): $4838-4844$. DOI: 10.1016/j.tet.2011.05.016.

Politycka B. 2007. Produktywność roślin. s. 353-372. W: „Fizjologia roślin, Od teorii do nauk stosowanych” (M. Kozłowska, red.). PWRiL, Poznań, 544 ss. ISBN 978-83-09-01023-4.

Praczyk T., Kardasz P., Jakubiak E., Syguda A., Materna K., Pernak J. 2012. Herbicidal ionic liquids with 2,4-D. Weed Science 60 (2): 189-192. DOI: 10.1614/WS-D-11-00171.1.

R Core Team 2016. R: A language and environment for statistical computing. R Foundation for Statistical Computing, Vienna, Austria. https://www.R-project.org [Accessed: 15.02.2017].

Shamshina J.L., Kelley S.P., Gurau G., Rogers R.D. 2015. Chemistry: Develop ionic liquid drugs. Nature 528 (7581): 188-189. DOI: $10.1038 / 528188 \mathrm{a}$.

Starck Z. 2008. Stresy wynikające z nieprawidłowego odżywiania roślin azotem. [Stresses provoked by incorrect nitrogen nutrition in plants]. Postępy Nauk Rolniczych 60 (1): 27-42.

Tatagiba S.D., DaMatta F.M., Rodrigues F.A. 2016. Magnesium decreases leaf scald symptoms on rice leaves and preserves their photosynthetic performance. Plant Physiology and Biochemistry 108: 49-56. DOI: 10.1016/j.plaphy.2016.07.002.

Tatarková V., Hiller E., Vaculík M. 2013. Impact of wheat straw biochar addition to soil on the sorption, leaching, dissipation of the herbicide (4-chloro-2-methylphenoxy)acetic acid and the growth of sunflower (Helianthus annuus L.). Ecotoxicology and Environmental Safety 92: 215-221. DOI: 10.1016/j.ecoenv.2013.02.005.

Tränkner M., Jákli B., Tavakol E., Geilfus Ch., Cakmak I., Dittert K., Senbayram M. 2016. Magnesium deficiency decreases biomass water-use efficiency and increases leaf water-use efficiency and oxidative stress in barley plants. Plant Soil 406 (1-2): 409-423. DOI: 10.1007/s11104-016-2886-1.

Wang M., Zhou Q. 2006. Effects of herbicide chlorimuron-ethyl on physiological mechanisms in wheat (Triticum aestivum L.). Ecotoxicology and Environmental Safety 64 (2): 190-197. DOI: 10.1016/j.ecoenv.2005.03.032.

Žaltauskaitė J., Brazaitytė V. 2013. Assessment of the effects of sulfonylureas herbicide amidosulfuron application on target and non-target organisms. Fresenius Environmental Bulletin 22 (7 A): 1977-1982.

Žaltauskaitė J., Kišonaite G. 2014. The effects of phenoxy herbicide MCPA on non-target vegetation in spring wheat (Triticum aestivum L.) culture. Biologija 60 (3): 148-154. DOI: 10.6001/biologija.v60i3.2974. 